\title{
The effect of four factors on parallelism in English sentence
}

\section{Dina. M. Salman}

AL-Turath University College, Baghdad, Iraq

\begin{abstract}
This article is an attempt to the shed the light on the importance of using parallelism in English sentences. The parallel sentences are easily read and comprehendon the contrary of the non-parallel sentences which create confusion and ambiguity. However parallelism facilitates the production and comprehension of the recipients. This positive effect of parallelism is affected and restricted by four factors which can reduce its influence.This work tries to memorize these main factors and show the difference in the interpretations and comprehension of the sentences when they are parallel and non parallel.
\end{abstract}

Keywords-parallelism in English sentence, conjunctions, comprehension.

\section{INTRODUCTION}

Humans are prone to scrutinize, analyze and comprehend the mechanism of the linguistic structure of the sentence in order to facilitate their messages when they are interacting. Parallelism provides simplicity and facilitation to both the cooperators and the coordination process. Parallelism means the repetition and the commitment of the same structure when we combine sentences by conjunctions which are of variant kinds. The coordinated conjunctions such as and, but, or, nor, than and yet; the second kind is subordinate conjunctions such as while; the third type is correlative conjunctions such as either...or, neither...nor, but...also, not only and if...then and finally the relative clauses which use that, which, who to combine sentences. The agreement between the two conjuncts is very necessary to ease and increase the comprehension (Altmann, Henstra\&Granham 1993) and production (Bock 1986 and many subsequent studies). It makes our speech run smoothly and our writing become clearer and more powerful.

In fact, parallelism has impact on the different aspects of language such as phonology (Carlson, 2001; Frazier et al. 1984), syntax, semantics (Kutas, 1993) and animacy (Carlson, 2001; Frazier et al. 1984). This influence is called parallelism effect. Here a question raises: what are the factors which affect the parallelism effect? In what follows, an attempt is given to summarize the most important factors which play remarkable roles in the parallelism effect.

\subsection{Parallelism and the gapping}

Many researchers like Frazier et al. (1984) find it is easy to grasp the ideas and thoughts when they are shown in a similar structure in both conjoined sentences, for example:

1.a. the black man hits the child and the while man hits the old.

1.b. the black man hits the child and the old is hit by the white man.

The recipient finds facilitation when he reads (1.a) rather than (1.b) because the second conjunct is of the same grammatical structure as the first sentence, so it glides smoothly from the first sentence to the second without interruption. But (1.b) there is a pause which cuts the smooth current of the constituent order of comprehension in the second sentence.

Frazier et al.(2000) have many opinions concerning this phenomenon. They thought this facilitation can be interpreted according to many possibilities; one of them is that both nouns in both conjoined sentences are preceded by determiner; the other opinion is the approximate length of the syllable in the two conjuncts which can be named as the effect of parallelism in phonology.

Is the repetition of the verb necessary?

Aria et al. (2007), Branigan et al (2005), Pickering \& Ferreira (2008) state the repetition is very emergent one to pursue the parallelism effect. While Traxler (2008) and 
Knoeferle\& Crocker (2009) affirm that the repetition of the prime verb doesn't affect strongly the parallelism facilitation.

The omitted material from the second conjunct contains the verb or may be the object (Johnson 1997, Kuno 1976, Sag 1980). The tendency of the parallelism effect to the nongapping elements in the conjoined sentences is more than to the gapping one and when the second conjunct sometimes lacks the verb (missing), we assume that it holds the same priming verb. Then the sentence is an ambiguous one.

Now consider the following sentences:

1. Jane took the children to the school and Janet to the mall.

2. My mum gave me a bread and others cookie.

In (1) the second sentence contains of mere noun and pp. Janet is whether the subject and the post verbal for the verbless second sentence or the object for the priming sentence. The same interpretation is with (2).

The interpretations for the sentence:

1- Jane took the children to the school and Janet took the children to the mall.

2- Jane took the children to the school and she took Janet to the mall.

Frazier, Clifton \& Munn (2000) state that:

Parallelism did not facilitate
processing when the structure of
a subject and object were
manipulated, implying that
parallelism effect are largely
limited to the conjuncts of a
coordinate structure and not due
simply to the repetition of a
phrase with a particular shape.

These ambiguities affect the parallelism effect and restrict its influence. This will lead us to the second factor: Does the parallelism effect depend on the surface or internal structure of the sentence?

\subsection{Parallelism and the linguistic features}

Psychologically the listener finds easy to grasp the parallel structure than the non-parallel structure. Frazier et al. (1984) find facilitation in reading the second parallel structure rather than thenon-parallel structure. According to Chomsky (1957) the two conjuncts should be structurally compatible. It means they must be of like syntactic categories. In spite of the different syntactic category of the conjoined sentences, they are still grammatical acceptable.

Nevertheless, the parallelism sometimes is in the internal structure and it depends on the context not on the surface structure only.Knoeferle(2014) affirms that the facilitation of parallelism comes either from the constituent order of the sentence or from the modulation of the linguistic context.

Munn $(1992,1993,1999)$ states that the parallelism can be between the sentences which have the same semantic features. Gazdar, Klein, Pullum\& Sag 1985; Pollard \& Sag, Gazdar, Wasow\&Weister 1985 emphasize the unification of the two conjuncts which means they share the same characteristic features and categories. For instance:

1- Jane wants to travel tomorrow or on Sunday.

2- Jane runs quickly but with quite care.

3-Jane runs quickly and to the garage.

In the first two sentences the adverbs (tomorrow), (on Sunday), (quickly) and (quite care) each parallel sentenceshas the same semantic feature of the adverb while the third sentence (quickly) and (to the garage) are different in their semantic categories; the first one is adverb of manner while the second is of goal.The unlike semantic feature of (3) affects the parallelism facilitation and reducesits effect.

\subsection{Parallelism and Prosody}

Prosody deals with the suprasegments such as rhythm, intonation, tone, stress (wikipedia). It plays a significant role in the parallelism effect and on the auditory processing of the sentence Carlson (2001) for it gives the sense of the intended message the speaker wants to convey. Lehiste, 1973; Price, Ostendorf, Shattuck-Hufngel\& Fong, 1991 state that prosody's contribution to parallelism is to make the sentence as unambiguous one.

The study of the relation between the prosody and the influence of parallelism isn't recent study but it belongs to many decades ago (Culter, Dahan, \& van Donselaar 1997. Carlson(2001) assumed that the absence of prosody leads the ambiguity to the sentence. The interpretations as we mentioned before for the sentence which has gapping elements, the prosody is necessary (kjelgaard, 1995; Speer, kjelgaard, \&Dobroth, 1996) to solve the ambiguous problem. But the prosody's effect isn't beneficial in the sentence's analysis. The effect of prosody on parallelism is called prosodic parallelism which can be used as a bridge between the gapping and non-gapping analysis of the sentences Carlson(2001). For the gapping sentence, the using of 
prosodies is the crucial point which can distinguish the intended meaning.

One of the prosody's elements is pitch accents. Pitch accent is useful as many researchers find(Birch \& Clifton, 1995; Schafer, Carlson, Clifton, \& Frazier, 2000; Schafer, Carter, Clifon, \& Frazier, 1996) when it marks the deferential point between the first and the second conjuncts. For instance:

- John shocked the teachers with his flúency and Jack with his appéarance.

In this sentence whether we consider it a gapping or nongapping sentence, the two words (flúency and appéarance) are different, thus the location of the pitch accent on the specific element is very important to determine the contrastive points between the two conjuncts. However, the similarity of using the same pitch accent over the same syntactic element in both conjoined sentences will increase the effect of parallelism in spite of their contradictions.

\subsection{The number of the elements between the verb and its particle.}

The facilitation of the parallelism becomes more influential when the number of elements between the verb and its preposition is lessand vice versa. Dubey et al. (2005) said "particle verbs are of particular interest for the investigation of parallelism, because they allow for a syntactic alternation which has only a minimal effect on meaning". Consider the following example:

1- Jane felt sick and she took off the cigarette.

2- Jane felt sick and she took the cigarette off.

In the sentences (1) and (2),Dubey et.al. (2014) assumed that we have in our consideration two factors; the obvious syntactic continuentconcerning parallelism in (1) and the phonological factors in (2) concerning of the variant syllables which separate between the verb and its preposition. The continuent stream of the sentence psycholiguistically becomes difficult and this difficulty can be explained according to other linguistic features. The facilitation in (1) is clearer than in (2) because the number of separated elements in (1) is less than in (2). Both sentences has identical meaning but different structure. However the meaning of sentence (1) is little affected by the syntactic exchange and this affects the parallelism effect as a result.

\section{CONCLUSION}

Parallelism plays a remarkable role in the sentences' comprehension, production and interpretation. It gives the sentence a kind of clarity, easy and smoothness which the non-parallel sentences lacks. In the previous papers, we conclude that there are factors affect the influence of the parallelism and reduce its effect. One of these factors is the gapping or missing element in the second sentence which leads to ambiguity and finally misleads the addressee. The second factor is the number between the verb and its particle. Whenever the number of the elements increases, the parallelism effect reduces. The third factor is: if we depend on the surface structure of the sentence or on the internal structure or context. In fact, if we restrict ourselves with the surface structure of the sentence, many realities will be vanished and marginalized. For this sake, if we go further inside the deep structure of the sentence, we will find similarity either in category or kind. As a result, this fact will help parallelism to pursue to achieve its purpose. The ultimate factor as a researcher's point of view is the prosody and its invisible impact on the recipients' sense of the intended meaning of what is said.

\section{REFERENCES}

[1] Altmann, G., Henstra, J. \&Granham, A. (1993). Poster presented at Sixth Annual CUNY Conference on Human Sentence Processing. Amherst, MA.

[2] Arai, M., Gompel, R. P. G., \&Scheepers, C. (2007). Priming ditransitive structures in comprehension. Cognitive Psychology, 54, 218-250.

[3] Bock, J.K. (1986). Syntactic persistence in language production. Cognitive Psychology, 18, 355-387.

[4] Birch, S., \& Clifton, C. E. (1995). Focus, accent, and argument structure: Effects on language comprehension. Language and Sprrch, 38, 365-391.

[5] Branigan, H., Pickering, M. J., \& McLean, J. (2005). Priming prepositional phrase attachment during comprehension. Journal of ExperimentalPsychology: Learning, Memory, and Cognition, 31, 468-481.

[6] Carlson, K. (2001). The effects of parallelism and prosody in the processing of gapping structures. Language and Speech, 44, 1-26.

[7] Chomsky, N. (1957). Syntactic Structures. The Hague: Mouton.

[8] Culter, A., Dahan, D., \& Van Donselaar, W. (1997). Prosody in the comprehension of spoken language: A literature review. Language and speech, 14, 399-452.

[9] Dubey, A., Keller, F.\&Sturt, P. (2014). The Effect of phonological Parallelism in Coordination: Evidence from Eye- 
tracking. Human Communication Research Center, University of Edinburgh 2 Buccleuch Place, Edinburgh EH 89LW,UK.

[10] Dubey, A., Sturt, P., \& Keller, F. (2005). Parallelism in coordination as an instance of syntactic priming: Evidence from corpus-based modelling. In Processings of the Human Language Technology Conference and the Conference on Empirical Methodsin Natural Language Processing, (pp.827834), Vancouver.The Association for Computational Linguistics.

[11] Frazier, L.; Clifton, C. \& Munn, A. (2000). Processing Coordinate Structures. Journal of Psycholinguistic Research.

[12] Frazier, L., Taft, L., Roeper, T., Clifton, C. \& Ehrlich, K. (1984). Parallel Structure: A source of facilitation in sentence comprehension. Memory \& Cognition, 12, 421-430.

[13] Gazdar, G., Klein, E., Pullum, G. \& Sag, I. (1985). Generalized Phrase Structure Grammar. Cambridge MA: Harvard University Press.

[14] Johnson, K. (1997). Bridging the gap. In search of the English middle field, chap. 2. Ms.,University of Massachusetts, Amherst.

[15] Kjelgaard, M. M. (1995). The role of prosodic structure in yhe resolution of phrase-level and lexical syntactic ambiguity. Unpublished doctoral dissertation, Northeastern University.

[16] Knoeferle, Pia. (2014). Conjunction meaning can modulate parallelism facilitation: Eye-tracking evidence from German clausal coordination. Cognitive Interaction Technology Excellence Cluster \& Department of Linguistics, University of Bielefeld, Germany.

[17] Knoeferle, P., \& Crocker, M. W. (2009). Constituent order and semantic parallelism in online comprehension: Eye-tracking evidence from German. Quarterly Journal of Experimental Psychology, 62, 2338-2371.

[18] Kuno, S. (1976). Gapping: A functional analysis. Linguistic Inquiry, 7, 300-318.

[19] Kutas, M. (1993). In the company of other words: Electrophysiological evidence for single-word and sentence context effects. Language and Cognitive Processes, 8, 533572.

[20] Lehiste, I. (1973). Phonetic disambiguation of syntactic ambiguity. Glossa, 7, 107-122.

[21] Munn, A.(1999, in press). First conjunct agreement: against a biclausal analysis, Linguistic Inquiry, 30.

[22] Munn, A.(1993). Topics in the syntax and semantics of coordinate structures. Doctoral dissertation, University of Maryland, College Park.

[23] Munn, A. (1992). A null operator analysis of ATB gaps. The linguistic Review, 9, 1-26.

[24] Pickering, M. J., \& Ferreira, V. (2008). Structural priming: A critical review.Psychological Bulletin, 34, 427-459.

[25] Sag, I. A. (1980). Deletion and logical form. New York: Garland Publishing.

[26] Pollard, C. \& Sag, I. (1994). Head-driven phrase Structure Grammar, Chicago:University of Chicago Press.
[27] Price, P., Ostendorf, M., Shattuck-Hufngel, S., \& Fong, C.(1991). The use of prosody in syntactic disambiguation. Journal of the Acoutical Society of America, 90,2956-2970.

[28] Sag, I., Gazdar, G., Wasow, T. \&Weisler, S. (1985). Coordination and how to distinguish categories. Natural Language and Linguistic Theory, 3, 117-171.

[29] Scheepers, C., \& Crocker, M. W. (2004). Constituent order priming from reading to listening: A visual-world study. In M. Carreiras\& C. Clifton, Jr. (Eds.), The on-line study of sentence comprehension: Eye tracking, ERPs, and beyond (pp. 167185). New York: Psychology Press.

[30] Scheepers, C, Clifton, C. E., \& Frazier, L. (2000). Focus and the interpretation of pitch accent: Disambiguating embedded questions.Language and Speech. 43. 75-105.

[31] Scheepers, C, Clifton, C. E., \& Frazier, L. (1996). Focus in relative clause construal. Language and Cognitive Processes, $11,135-163$.

[32] Speer, S., Kjelgaard, M., \&Dobroth, K. (1996). The influence of prosodic structure on the resolution of temporary syntactic closure ambiguities. Journal of psychlinguistic Research, 25, 249-271.

[33] Traxler, M. J. (2008). Lexically independent priming in online sentence comprehension. Psychological Bulletin and Review, $15,149-155$. 